\title{
Triptolide induces cell-cycle arrest and apoptosis of human multiple myeloma cells in vitro via altering expression of histone demethylase LSD1 and JMJD2B
}

\author{
Lu WEN ${ }^{1, \#}$, Yan $\mathrm{CHEN}^{1, \#}$, Ling-lan ZENG ${ }^{2}$, Fei ZHAO ${ }^{1}$, Rui $^{1}{ }^{1}$, Yuan LIU ${ }^{1}$, Chun ZHANG ${ }^{1, *}$
}

${ }^{1}$ Department of Hematology, Union Hospital, Tongji Medical College, Huazhong University of Science and Technology, Wuhan 430022, China; ${ }^{2}$ Department of Central Laboratory, Union Hospital, Tongji Medical College, Huazhong University of Science and Technology, Wuhan 430022, China

Aim: To elucidate the relationship between triptolide-induced changes in histone methylation and its antitumor effect on human multiple myeloma (MM) cells in vitro.

Methods: Human multiple myeloma cell line RPMI8226 was used. Apoptosis was evaluated using Annexin-V-FITC/PI-labeled flow cytometry, Hoechst 33258 staining, and transmission electron microscopy. Flow cytometry was used to detect the cell cycle distribution of the apoptotic cells. The presence of the LSD1, JMJD2B, H3K4me2, H3K9me2, and H3K36me2 proteins was verified by Western blot analysis. Semi-quantitative real-time PCR was performed to examine the expression of LSD1 and JMJD2B.

Results: Triptolide (10-160 nmol/L) suppressed the proliferation of $\mathrm{MM}$ cells in a dose- and time-dependent manner with an IC $\mathrm{C}_{50}$ value of $99.2 \pm 9.0 \mathrm{nmol} / \mathrm{L}$ at $24 \mathrm{~h}$. Triptolide $\left(50 \mathrm{nmol} / \mathrm{L}\right.$ ) induced $\mathrm{G}_{0} / \mathrm{G}_{1}$ cell cycle arrest in $M M$ cells. The agent (50-150 $\left.\mathrm{nmol} / \mathrm{L}\right)$ induced apoptosis of $\mathrm{MM}$ cells in a dose-dependent manner. The same concentrations of triptolide suppressed the expression of dimethylated H3K4, dimethylated H3K9 and dimethylated H3K36 by altering the expression of histone demethylase LSD1 and JMJD2B without affecting the expression of histone demethylase LSD1.

Conclusion: Triptolide potently inhibits the growth of MM cells via regulating the expression of histone demethylase LSD1 and JMJD2B, which lead to abnormal histone methylation.

Keywords: triptolide; multiple myeloma; apoptosis; cell cycle arrest; LSD1; JMJD2B

Acta Pharmacologica Sinica (2012) 33: 109-119; doi: 10.1038/aps.2011.145; published online 28 Nov 2011

\section{Introduction}

Tripterygium wilfordii is a perennial vine-like member of the Celastraceae plant family ${ }^{[1]}$. Extracts from this plant have recently been shown to possess anti-tumor effects against cancers, such as leukemia and lymphoma ${ }^{[2-6]}$. Triptolide induces apoptosis in AML cells via the downregulation of XIAP and upregulation of DR5 mediated by $\mathrm{p} 53^{[1,7]}$. Furthermore, triptolide upregulates the expression of glucocorticoid receptor and enhances PS-341-induced apoptosis via the PI3k/Akt/NFkappaB pathway in multiple myeloma (MM) cells ${ }^{[8]}$. Although the development of chemotherapy regimens has improved the remission rate of $\mathrm{MM}$, relapse is still inevitable.

Considerable evidence indicates that epigenetics is involved

\footnotetext{
\# These two authors contributed equally to this work.

* To whom correspondence should be addressed.

E-mail Zhangchun23@yahoo.com.cn

Received 2011-08-12 Accepted 2011-09-29
}

in the changes in gene expression that contribute to the pathogenesis of MM. The death-associated protein kinase (DAPK) promoter has been reported to be methylated in $\mathrm{MM}^{[9,10]}$. MM patients with DAPK hypermethylation respond relatively poorly to treatment ${ }^{[11]}$. DNA methylation-mediated gene silencing is a frequent event in MM and disrupts the cell cycle, cell invasion and adhesion, DNA repair, and apoptotic pathways $^{[12]}$.

Histone methylation modulates the structure and function of chromatin ${ }^{[13]}$. These modifications are regulated by two classes of enzymes with opposing activities: histone methyltransferases and demethylases. The balance between the methylation and demethylation of specific histone residues is critical for regulating gene expression. Aberrant expression of histone-modifying enzymes has been implicated in the initiation and progression of tumors ${ }^{[14]}$. Our previous studies showed that histone-trimethylated H3K9 and H3K27 and the methyltransferases SUV39H1 and EZH2 were highly 
expressed in triptolide-treated MM cells, which was the first evidence that triptolide induced epigenetic changes by regulating histone lysine methylation ${ }^{[15]}$.

LSD1 was the first histone lysine demethylase to be discovered and is highly specific for di- and mono-methylated H3K4 and H3K9; LSD1 has been identified as a component of transcriptional repressor complexes comprising transcriptional corepressor protein (CoREST) and HDAC1/2. ChIPDSL analyses revealed that LSD1 targets the promoters of an array of genes that are involved in several important cellular processes, including cellular growth, proliferation, apoptosis and fate specification. JMJD2B, a member of the JMJD2 family, which mainly consists of oncogenes, demethylates di- and trimethylated $\mathrm{H} 3 \mathrm{~K} 9$ and $\mathrm{H} 3 \mathrm{~K} 36^{614]}$. Compared with studies examining DNA methylation, studies on histone methylation, histone demethylases and their mechanisms of action in MM are scarce.

In this study, we aimed to investigate changes in the expression of the histone demethylases LSD1 and JMJD2B induced by triptolide in the MM cell line RPMI8226. We analyzed H3K4 dimethylation, H3K9 and H3K36 dimethylation states and examined the connections between apoptosis, histone methylation changes and demethylase regulation by triptolide to determine whether triptolide exerts its anti-myeloma effects through the regulation of histone demethylases in MM cells.

\section{Materials and methods Reagents}

Triptolide (empirical formula: $\mathrm{C}_{20} \mathrm{H}_{24} \mathrm{O}_{6}$, molecular weight: 360.40, purity: $>98 \%$; Figure 1) was purchased from SigmaAldrich (St Louis, MO, USA). Triptolide was dissolved in dimethylsulfoxide (DMSO), stored at $-20^{\circ} \mathrm{C}$, and thawed before use. RPMI-1640 medium was purchased from Gibco (Gaithersburg, MD, USA). Propidium iodide (PI), DMSO and 3-(4,5-dimethylthiazol-2-yl)-2,5-diphenyltetrazoliumbromide (MTT) were purchased from Sigma-Aldrich (St Louis, MO, USA). TRIzol for RNA extraction was purchased from Invitrogen (Carlsbad, CA, USA), and the cDNA synthesis kit was obtained from Toyobo Biologics. SYBR Green PCR master mix was purchased from Applied Biosystems (Foster City, CA, USA).

\section{Cell lines and culture}

The human MM cell line RPMI8226 was purchased from

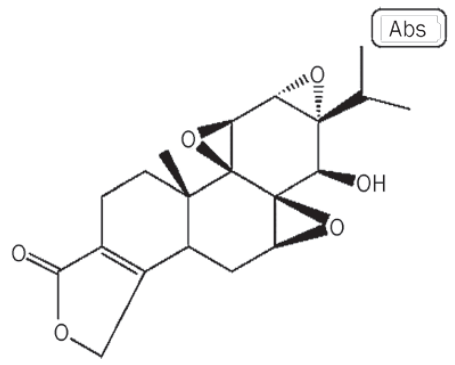

Figure 1. Chemical structure of triptolide.
Biomart Co Ltd (Shanghai, China); peripheral blood mononuclear cells (PBMCs) were isolated from the heparinized blood of healthy donors (after informed consent had been obtained) by Ficoll-Hypaque density gradient centrifugation. The two kinds of cells were maintained in RPMI-1640 medium supplemented with $10 \%(v / v)$ heat-inactivated fetal bovine serum, penicillin-streptomycin $(100 \mathrm{IU} / \mathrm{mL}, 100 \mu \mathrm{g} / \mathrm{mL}$, respectively), $2 \mathrm{mmol} / \mathrm{L}$ glutamine, and $10 \mathrm{mmol} / \mathrm{L}$ HEPES buffer at $37^{\circ} \mathrm{C}$ in a humidified $5 \% \mathrm{CO}_{2}$ atmosphere. During the expansion phase, RPMI8226 cells were maintained at a concentration of $0.5-1 \times 10^{6}$ cells $/ \mathrm{mL}$ in culture medium. The appropriate number of cells for use in the experiments was determined. RPMI8226 cells were treated with 50, 100, or $150 \mathrm{nmol} / \mathrm{L}$ triptolide for $48 \mathrm{~h}$, except where otherwise specified.

\section{Cell proliferation assay}

The anti-proliferative effect of triptolide in RPMI8226 cells was determined by MTT assay. RPMI8226 cells $\left(5 \times 10^{4}\right.$ per well $)$ were exposed to various concentrations of triptolide (0-160 $\mathrm{nmol} / \mathrm{L}$ ) for 24,48 , and $72 \mathrm{~h}$ in 96 -well plates. The experiments were performed in triplicate. After incubation with triptolide, $20 \mu \mathrm{L}$ MTT solution ( $5 \mathrm{mg} / \mathrm{mL}$ in PBS) was added to each well, the plates were incubated for $4-6 \mathrm{~h}$, the supernatants were discarded and $150 \mu \mathrm{L}$ of DMSO was added. Once the blue crystals were dissolved, the optical density $(O D)$ was measured at $570 \mathrm{~nm}$ using a 96-well multiscanner autoreader (Biotech Instruments, NY, USA). The inhibition of cell proliferation was determined using the following formula: inhibition of cell proliferation $(\%)=[1-(O D$ of the experimental samples $/ O D$ of the control $)] \times 100 \%(n=3$, mean \pm SD $)$. The triptolide concentration that caused $50 \%$ inhibition of cell proliferation was defined as half of the maximal inhibitory concentration $\left(\mathrm{IC}_{50}\right)$.

\section{Cell cycle distribution analysis}

RPMI8226 cells $\left(1 \times 10^{6}\right.$ cells/well) were treated with different concentrations of triptolide ( 0 or $50 \mathrm{nmol} / \mathrm{L}$ ) for $48 \mathrm{~h}$ and were harvested. After being washed, the cells were fixed with $75 \%$ ice-cold ethanol and were maintained overnight at $4{ }^{\circ} \mathrm{C}$. The cells were collected and resuspended in PBS containing 40 $\mu \mathrm{g} / \mathrm{mL}$ PI, $0.1 \mathrm{mg} / \mathrm{mL}$ RNase, and $5 \%$ Triton X-100 and were incubated at $37^{\circ} \mathrm{C}$ for $30 \mathrm{~min}$. The cells were evaluated by flow cytometry (BD, San Diego, CA, USA). Data was collected from at least 10000 cells for each sample. The distribution of cells across the cell-cycle phases was analyzed using CELLQuest.

\section{Annexin-V/PI staining assay}

An immunofluorescent flow cytometry assay was used to evaluate the ability of triptolide to induce apoptosis in RPMI8226 cells. The cells were seeded in 6 -well plates $\left(1 \times 10^{6}\right.$ cells/well $)$ and treated with varying concentrations of triptolide. PBMCs from 12 healthy donors were treated with $150 \mathrm{nmol} / \mathrm{L}$ triptolide for $48 \mathrm{~h}$. The cells were harvested, washed with cold PBS, and were resuspended in $100 \mu \mathrm{L}$ binding buffer. Subsequently, phosphatidyl serine on the surface of apoptotic cells 
was detected using Annexin V/FITC and a PI apoptosis detection kit according to the manufacturer's instructions (Bender Med Systems Inc, Burlingame, CA, USA). The number of apoptotic cells was evaluated by flow cytometry (BD, San Diego, CA, USA). At least 10000 cells were analyzed.

\section{Hoechst 33258 staining assay}

Nuclear fragmentation was visualized by staining apoptotic nuclei with Hoechst 33258. Cells treated with varying concentrations of triptolide were collected and washed and were fixed with a mixture of acetic acid:ethanol (1:3) for $10 \mathrm{~min}$ before deposition onto polylysine-coated cover slips. The samples were subsequently permeabilized with $0.25 \%$ Triton X-100 for $5 \mathrm{~min}$ and stained with $1 \mu \mathrm{g} / \mathrm{mL}$ Hoechst 33258 for $30 \mathrm{~min}$ at $37^{\circ} \mathrm{C}$. The slides were mounted with glycerol-PBS, and the images were visualized and captured using a FV500 confocal microscope (Olympus, Tokyo, Japan).

\section{Morphological observation by transmission electron microscopy}

The ultrastructural appearance of the apoptotic cells was examined by transmission electron microscopy. After incubation with $150 \mathrm{nmol} / \mathrm{L}$ triptolide for $48 \mathrm{~h}$, the cells were harvested and pre-fixed with $2 \%$ glutaraldehyde, post-fixed with $1 \%$ osmic acid, dehydrated in graded ethanol, embedded in resin, and cut into sections on an ultramicrotome. The ultrathin sections were doubly stained with uranyl acetate and lead citrate and were examined by transmission electron microscopy using a Hitachi H-7500 instrument (Hitachi, Tokyo, Japan).

\section{Western blot analysis}

Western blot analysis was used to evaluate the levels of LSD1, JMJD2B, and histones (dimethylated H3K4, dimethylated H3K9, and dimethylated H3K36) present in RPMI8226 cells exposed to triptolide.

Cells were treated with varying concentrations of triptolide and collected. The sample lysates ( $25 \mu \mathrm{g}$ of protein per lane) were prepared, and the proteins were separated by sodium dodecyl sulfate polyacrylamide gel electrophoresis on $10 \%$ polyacrylamide gels. The proteins were electro-transferred onto polyvinylidene difluoride membranes, and the blots were incubated with a blocking solution ( $5 \%$ non-fat dry milk in Tris-buffered saline with $0.1 \%$ Tween-20) for $1 \mathrm{~h}$ at $25^{\circ} \mathrm{C}$. The membranes were subsequently incubated with diluted primary antibodies (1:500-1:1000, Table 1$)$ for $2 \mathrm{~h}$. The mem- branes were washed and incubated with horseradish peroxidase-conjugated secondary antibodies (Pierce Biotechnology, Rockford, IL, USA) for $1 \mathrm{~h}$ at $25^{\circ} \mathrm{C}$. The immune complexes were visualized using the enhanced chemiluminescence reagent Super Signal Substrate (Pierce Biotechnology, Rockford, IL, USA). The band intensity was measured and quantified with a chemiluminescence detection system (ChemiDoc XRS, Bio-Rad, USA). The protein levels were normalized relative to $\beta$-actin, and each group was subsequently normalized to the control $(100 \%)$.

\section{Real-time PCR analysis}

Total RNA was isolated from each group using TRIzol according to the manufacturer's instructions. For each sample, $3 \mu \mathrm{g}$ total RNA was reverse transcribed into cDNA. Realtime quantitative PCR was performed with SYBR Green PCR master mix in an ABI Prism 7900 Sequence Detection System (Applied Biosystems, Foster City, CA, USA).

All mRNA expression levels are expressed as a ratio relative to the control in each experiment, and $\beta$-actin was used as internal reference. The following primers for human genes were used: LSD1 forward, 5'-GTGTCTCGTTGGCGTGCT-3', reverse, 5' -CCCGCAAAGAAGAGTCGTG-3'; JMJD2B forward, 5'-GGAAGCGGATGAAGAAGGTG-3', reverse, $5^{\prime}$-GGTAGTACAGCCCGTTGCG- $3^{\prime} ; \beta$-actin forward, 5'-GCCCAGTCCTCTCCCAAGTC-3', reverse, 5' -GGCACGAAGGTCATCATTC-3'.

\section{Immunofluorescence staining}

An immunofluorescence staining assay was performed to evaluate the effects of triptolide on LSD1 expression in MM cells. The cells were fixed with $4 \%$ paraformaldehyde for $10 \mathrm{~min}$ and were permeabilized with $0.25 \%$ Triton X-100 for $5 \mathrm{~min}$. The cells were subsequently washed twice with PBS and blocked in $3 \%$ bovine serum albumin. The rabbit monoclonal antiLSD1 antibody was diluted 1:100 and incubated with $1 \times 10^{6}$ cells in a total volume of $100 \mu \mathrm{L}$ for $1 \mathrm{~h}$; non-immunoreactive IgG was used as a negative control. After being washed, the cells were incubated for $1 \mathrm{~h}$ with a TRITC-labeled goat antirabbit secondary antibody (Pierce, Rockford, USA), diluted in PBS and were stained with Hoechst $33258(10 \mu \mathrm{g} / \mathrm{mL})$ for $10 \mathrm{~min}$. Images were visualized and captured using a FV500 confocal microscope (Olympus, Tokyo, Japan). The LSD1 levels were estimated as the mean fluorescence intensity after subtracting the fluorescence of the negative control cells. The

Table 1. Information about the primary antibodies used for Western blot and immunofluorescence staining.

\begin{tabular}{|c|c|c|c|c|}
\hline Antibody & Company & Catalog & Source & Molecular weight \\
\hline Anti-H3K4me2 & Upstate & \#07-436 & Rabbit polyclonal antibody & $17 \mathrm{kDa}$ \\
\hline Anti-H3K9me2 & Upstate & \#07-212 & Rabbit polyclonal antibody & $17 \mathrm{kDa}$ \\
\hline Anti-LSD1 & Cell Signaling & \#2139 & Rabbit monoclonal antibody & $150 \mathrm{kDa}$ \\
\hline Anti-JMJD2B & Cell Signaling & \#2898 & Rabbit monoclonal antibody & $110 \mathrm{kDa}$ \\
\hline
\end{tabular}


anti-JMJD2B antibody cannot be used for immunofluorescence staining.

\section{Statistical analysis}

The data are expressed as the mean \pm SD of three independent experiments. Also, $t$-tests were used to evaluate the differences between treated samples and controls. A $P$ value $<0.05$ was considered to be significant.

\section{Results}

\section{Effects of triptolide on the proliferation of RPMI8226 cells}

The inhibitory effect of triptolide on MM cell proliferation was examined in RPMI8226 cells. Figure 2 shows that triptolide had a dose- and time-dependent anti-proliferative effect on RPMI8226 cells at $0-160 \mathrm{nmol} / \mathrm{L}$ after exposure for 24,48 , and $72 \mathrm{~h}$. The number of viable cells decreased as the concentration of triptolide increased. The $\mathrm{IC}_{50}$ value at $24 \mathrm{~h}$ was $99.2 \pm 9.0$ $\mathrm{nmol} / \mathrm{L}$. As the exposure time increased, the $\mathrm{IC}_{50}$ values gradually decreased. The $\mathrm{IC}_{50}$ values after 48 and $72 \mathrm{~h}$ of treatment were $61.6 \pm 5.8 \mathrm{nmol} / \mathrm{L}$ and $23.3 \pm 2.6 \mathrm{nmol} / \mathrm{L}$, respectively.

\section{Triptolide induced RPMI8226 cell-cycle arrest}

To investigate whether triptolide was able to inhibit DNA synthesis, the effect of triptolide on cell-cycle progression in

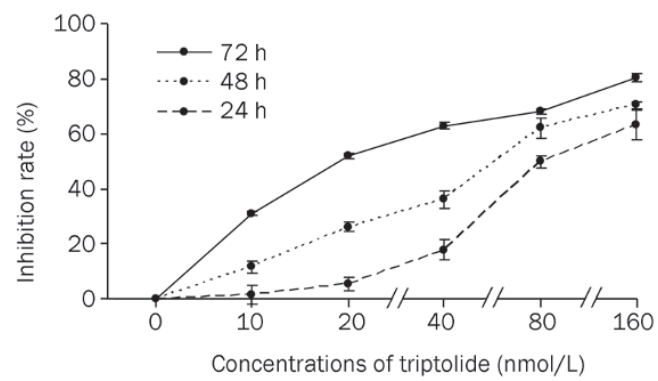

Figure 2. Anti-proliferation effect of triptolide on RPMI8226 cells. RPMI8226 were treated for $24,48,72 \mathrm{~h}$, respectively with increasing concentrations of triptolide $(0,10,20,40,80,160 \mathrm{nmol} / \mathrm{L})$. Inhibition rate was measured by MTT assay which is described in Materials and methods. Mean \pm SD. $n=3$.
RPMI8226 cells was measured by flow cytometry. After incubation with triptolide at $50 \mathrm{nmol} / \mathrm{L}$ for $48 \mathrm{~h}$, RPMI8226 cells were analyzed for alterations in their cell-cycle distribution (Figure 3); the proportion of $\mathrm{G}_{0} / \mathrm{G}_{1}$ phase cells significantly increased following the treatment with triptolide, with the $G_{2}$ phase cells also increasing slightly. Meanwhile, the fraction of cells in S phase decreased accordingly. This result indicates that triptolide-induced apoptosis is cell cycle-dependent (Table 2).

Table 2. The cell cycle distribution was quantified in triptolide $(50 \mathrm{nmol} / \mathrm{L}$, $48 \mathrm{~h}$ ) -treated and control cells. Mean \pm SD. $n=3$.

\begin{tabular}{lcccc}
\hline \multirow{1}{*}{ Triptolide } & \multicolumn{4}{c}{$\mathrm{RPMI8226}$} \\
& $\mathrm{G}_{1}(\%)$ & $\mathrm{S}(\%)$ & $\mathrm{G}_{2}(\%)$ & $\mathrm{G}_{2} / \mathrm{G}_{1}$ \\
\hline Control & $29.2 \pm 0.5$ & $69.7 \pm 0.7$ & $1.2 \pm 0.2$ & $1: 1.88$ \\
$50 \mathrm{nmol} / \mathrm{L}(48 \mathrm{~h})$ & $60.2 \pm 0.5$ & $31.6 \pm 0.8$ & $8.2 \pm 0.5$ & $1: 1.89$ \\
\hline
\end{tabular}

\section{Triptolide induced apoptosis in RPMI8226 cells and PBMCs}

Apoptosis induction by triptolide was observed in RPMI8226 cells using various methods. In Figure 4, the degree of apoptosis, as measured by flow cytometry, is quantitatively expressed as the percentage of cells that were Annexin V-positive in the presence of triptolide. For the triptolide concentrations in the range 50-150 nmol/L, the total percentage of apoptotic cells, designated as Annexin V-positive and PI-negative cells, gradually increased from $26.0 \% \pm 0.6 \%$ to $40.3 \% \pm 0.9 \%$, which was statistically different from the control $(2.9 \% \pm 0.3 \%)$.

In addition, we observed the effects of triptolide on apoptosis in RPMI8226 cells by visualizing the Hoechst 33258 staining of live cell nuclei using laser scanning confocal microscopy. Nuclei in the control cells were regular in shape. However, the cells became shrunken and dark after treatment with 50 nmol/L triptolide, and the nuclei showed chromatin condensation and marginalization or nuclear beading. The number of apoptotic cells gradually increased as the triptolide concentration increased, and at high concentrations (100 or $150 \mathrm{nmol} / \mathrm{L})$,

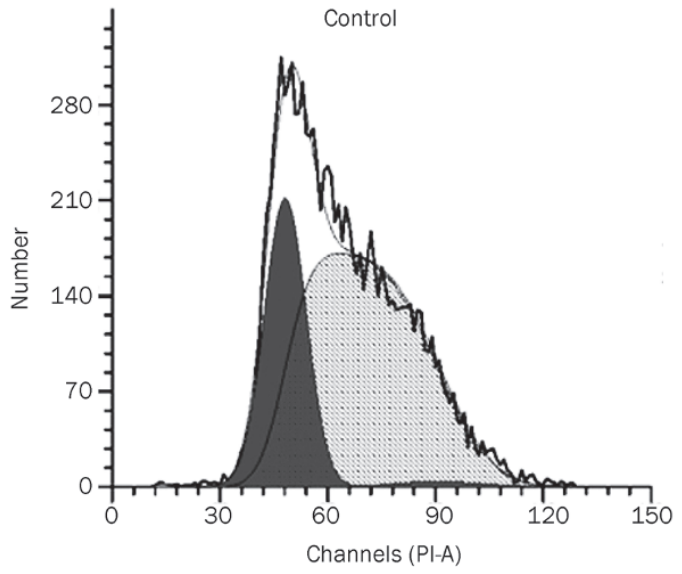

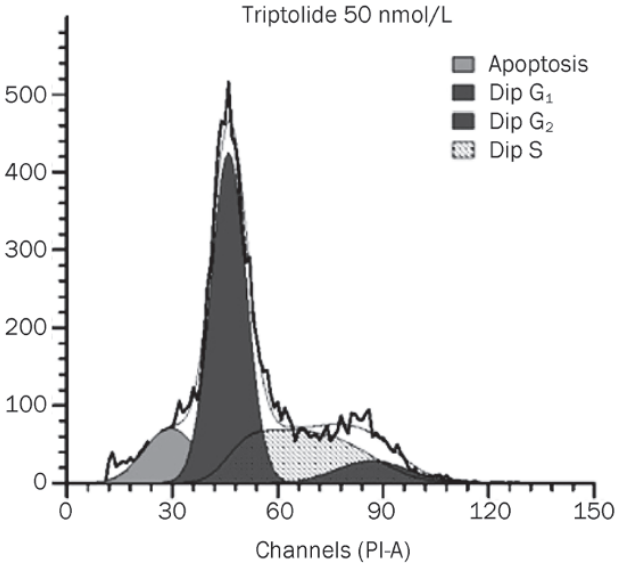

Figure 3. Effects of triptolide on cell cycle distribution in RPMI8226 cells. Cells were treated for $48 \mathrm{~h}$ with triptolide $(50 \mathrm{nmol} / \mathrm{L})$. The distribution of cell cycle was detected by $\mathrm{PI}$ staining. 

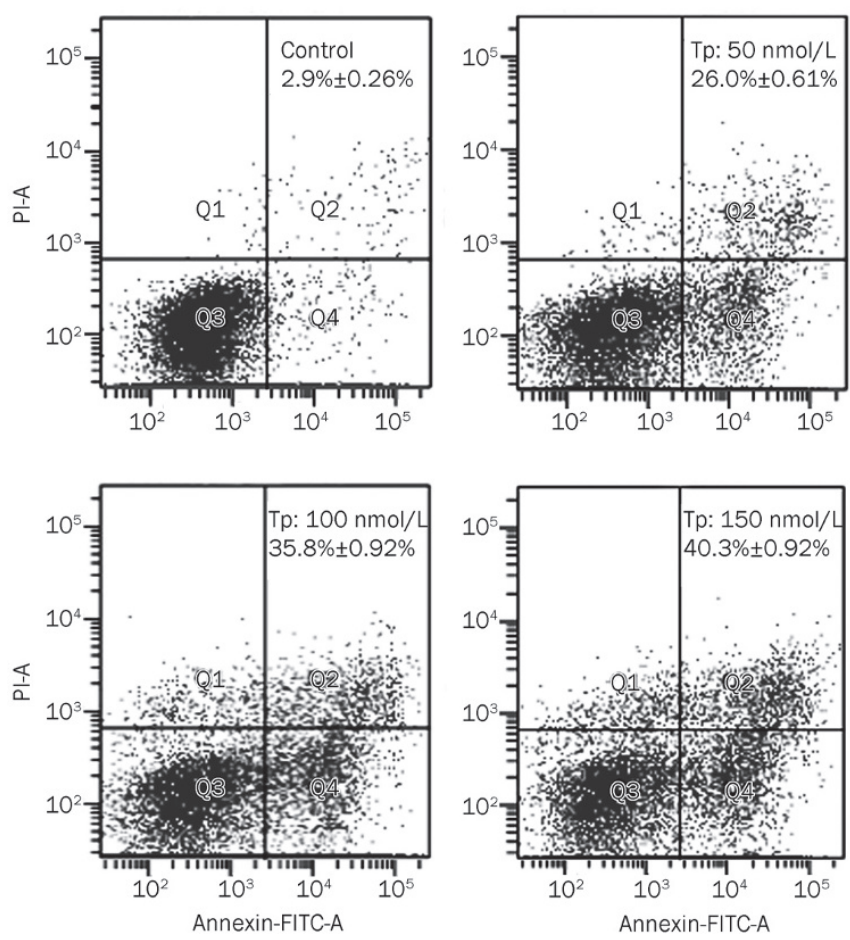

Figure 4. Effects of apoptosis induced by triptolide (Tp) on RPMI8226 cells. RPMI8226 cells were treated for $48 \mathrm{~h}$ with increasing triptolide (50, $100,150 \mathrm{nmol} / \mathrm{L}$ ) and suspended in $100 \mu \mathrm{L}$ binding buffer and Annexin $\mathrm{V} / \mathrm{PI}$ double staining solution. Apoptosis was then measured by flow cytometry. The figure showed the percentage of apoptosis cells increased in a dose-dependent manner. These figures are one representative experiment of three with similar results.

the cells showed morphological features typical of apoptotic cells (Figure 5).

To confirm further the induction of apoptosis by triptolide and to visualize better the ultrastructural changes occurring in MM apoptotic cells, we also used electron microscopy. Apoptotic bodies were observed in triptolide-treated cells; these bodies are spherical protuberances containing fragmented and segregated chromatin clumps separating from the cell surface (Figure 6). Conversely, the untreated RPMI8226 cells
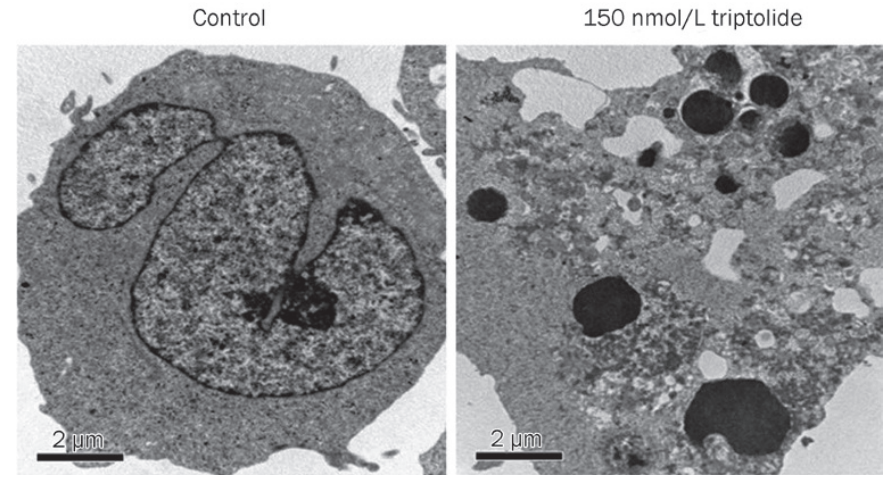

Figure 6. Apoptotic cells ultrastructural changes were viewed by transmission electron microscope with triptolide $(150 \mathrm{nmol} / \mathrm{L})$ treatment. The typical apoptotic bodies in triptolide-treated cells were spherical protuberances containing fragmentation and segregation of chromatin clumps separated from cell surface. However, the untreated RPMI8226 cells presented intact plasma membrane and orderly chromatin folding.

had intact plasma membranes and ordered chromatin folding (Figure 6).

The experiments to detect apoptosis by flow cytometry were also performed on PBMCs isolated from 12 healthy donors after the cells had been treated with $150 \mathrm{nmol} / \mathrm{L}$ triptolide for $48 \mathrm{~h}$. The amount of apoptosis induced by triptolide increased in 8 of the 12 donors (75\%), but only 2 donors (17\%) showed an increase of more than $30 \%$, and 5 donors (41.7\%) showed an increase of more than $20 \%$ (Table 3 ).

\section{Triptolide decreased dimethylated H3K4 expression}

H3K4 methylation is generally associated with active transcription $^{[16]}$. RPMI8226 cells were treated with triptolide concentrations of 50,100, or $150 \mathrm{nmol} / \mathrm{L}$ for $48 \mathrm{~h}$. The levels of dimethylated H3K4 were measured by Western blot analysis. As shown in Figure 7B, the expression of dimethylated H3K4 decreased in a dose-dependent manner, and the rates of inhibition by 50,100 , and $150 \mathrm{nmol} / \mathrm{L}$ of triptolide were $17.5 \%$, $53.6 \%$, and $70.3 \%$, respectively ( $P<0.05$ vs untreated control). We also found that the global trimethylated H3K4 level decreased in a dose-dependent manner after treatment with

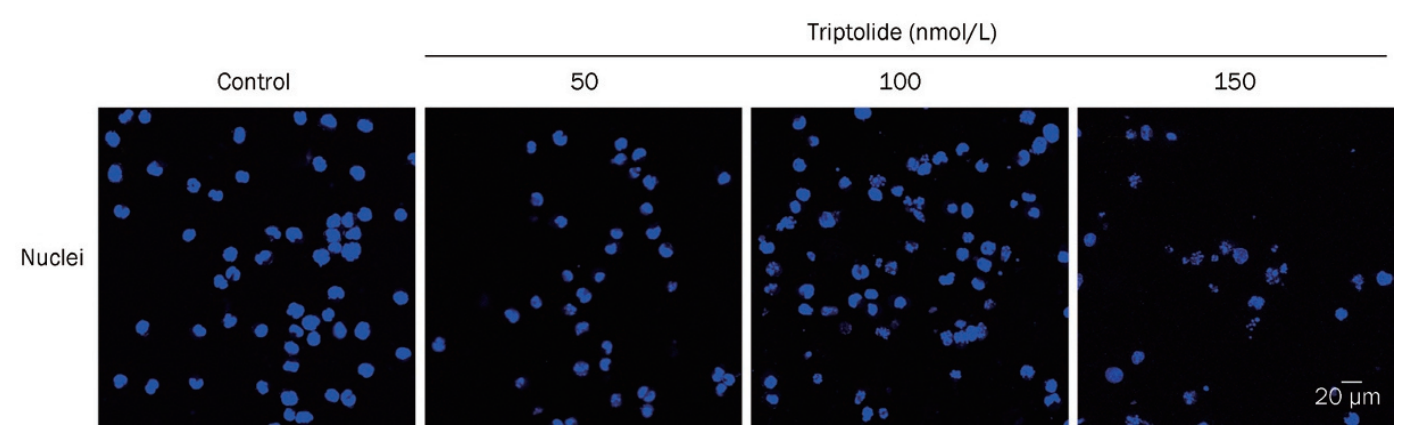

Figure 5. Triptolide induced apoptosis in RPMI8226 cell lines. Apoptotic cell death was revealed by Hoechst 33258 staining with increasing triptolide (50, $100,150 \mathrm{nmol} / \mathrm{L}$ ) treatment. Apoptotic cells exhibited highly condensed and fragmented nuclei morphology. Results showed that number of apoptotic cells increased with the increasing concentrations. 
increasing triptolide concentrations in another MM cell line, $\mathrm{U} 266^{[17]}$.

Table 3. Apoptosis of PBMC from 12 healthy persons treated with triptolide (150 nmol/L, $48 \mathrm{~h}$ ).

\begin{tabular}{rccccrr}
\hline & & \multicolumn{4}{c}{ Control (\%) } & \multicolumn{2}{c}{ T-treated (\%) } \\
& Gender & $\begin{array}{c}\text { Age } \\
\text { (year) }\end{array}$ & $\begin{array}{c}\text { Early } \\
\text { apoptosis }\end{array}$ & $\begin{array}{c}\text { Late } \\
\text { apoptosis }\end{array}$ & $\begin{array}{r}\text { Early } \\
\text { apoptosis }\end{array}$ & $\begin{array}{r}\text { Late } \\
\text { apoptosis }\end{array}$ \\
& & & & & & \\
\hline 1 & M & 26 & 3.9 & 3.2 & 3.5 & 3.6 \\
2 & M & 53 & 7.1 & 1.3 & 38.3 & 10.1 \\
3 & F & 48 & 5.1 & 2.9 & 30.8 & 15.6 \\
4 & M & 40 & 22.3 & 3.5 & 45.8 & 6.5 \\
5 & M & 56 & 53.3 & 3.1 & 54.7 & 3.6 \\
6 & M & 55 & 30.9 & 5.9 & 36.6 & 10.2 \\
7 & M & 58 & 3.6 & 12.2 & 14.4 & 26.4 \\
8 & F & 61 & 8.9 & 16.2 & 19.3 & 33.5 \\
9 & F & 24 & 10.9 & 4.5 & 19.1 & 3.6 \\
10 & M & 31 & 21.8 & 3.9 & 36.1 & 2.9 \\
11 & M & 26 & 8.9 & 2.3 & 7.8 & 3.5 \\
12 & M & 27 & 7.9 & 3.9 & 3.9 & 3.5 \\
\hline
\end{tabular}

\section{Triptolide decreased dimethylated H3K9 expression}

To date, H3K9 methylation has been examined primarily at repressed promoter regions and is thought to act as a docking site for the chromodomain of HP1. H3K9 methylation and HP1 were also found to be associated with the transcribed regions of all active genes examined ${ }^{[13]}$. RPMI8226 cells were treated with triptolide concentrations of 50,100, or $150 \mathrm{nmol} / \mathrm{L}$ for $48 \mathrm{~h}$. After triptolide treatment, the levels of dimethylated H3K9 were measured by Western blot analysis. The global levels of dimethylated H3K9 significantly decreased after exposure to triptolide. The rates of inhibition by 50, 100, and $150 \mathrm{nmol} / \mathrm{L}$ triptolide were $34.7 \%, 29.4 \%$, and 39.6\%, respectively; $(P<0.05$ vs untreated control) (Figure $7 \mathrm{~B})$. We also found that the expression of trimethylated H3K9 decreased in RPMI8226 cells, and monomethylated H3K9 was elevated in U266 cells in a dose-dependent manner following treatment with increasing concentrations of triptolide ${ }^{[15,18]}$.

\section{Triptolide decreased dimethylated H3K36 expression}

H3K36 methylation has primarily been characterized as an active mark that facilitates transcriptional elongation ${ }^{[19]}$. RPMI8226 cells were treated with triptolide concentrations of
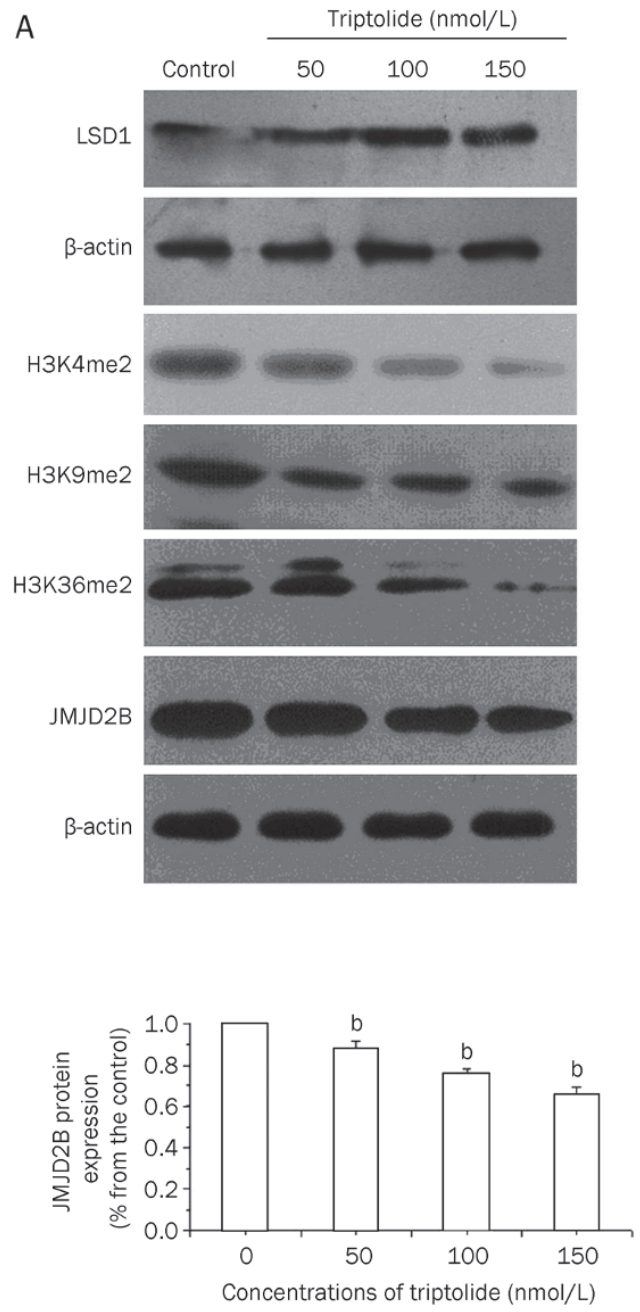
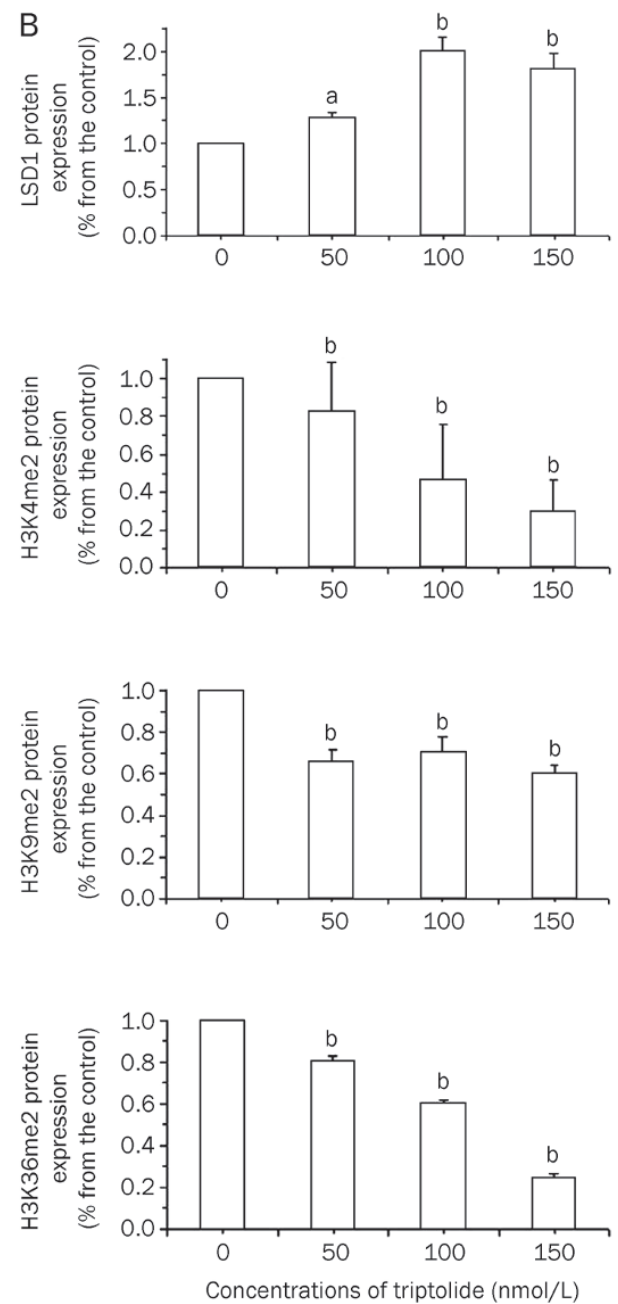

Figure 7. (A) Effects on the protein expression of $\mathrm{H} 3 \mathrm{~K} 4 \mathrm{me} 2$, H3K9me2, H3K36me2, histone demethylase LSD1 and JMJD2B. RPMI8226 cells were treated with various concentrations $(50,100$, $150 \mathrm{nmol} / \mathrm{L}$ ) triptolide for $48 \mathrm{~h}$, then cell lysates were subjected to SDS-PAGE followed by Western blotting with anti-H3K4me2, antiH3K9me2, anti-H3K36me2, antiLSD1, anti-JMJD2B antibodies. Each membrane was then stripped and reprobed with anti- $\beta$-actin antibody to confirm equal protein loading. (B) The statistical results of protein expression of $\mathrm{H} 3 \mathrm{~K} 4 \mathrm{me} 2$, H3K9me2, H3K36me2, LSD 1 and JMJD2B. Mean \pm SD. $n=3$. ${ }^{\mathrm{a}} \mathrm{P}>0.05 .{ }^{\mathrm{b}} P<0.05$ vs control. 
50, 100, or $150 \mathrm{nmol} / \mathrm{L}$ for $48 \mathrm{~h}$. Western blot analysis with an antibody against H3K36me2 was used to measured histone H3K36 dimethylation. Triptolide treatment for $48 \mathrm{~h}$ led to a significant reduction in the level of H3K36me2 in a dosedependent manner. The rates of inhibition by 50,100, and $150 \mathrm{nmol} / \mathrm{L}$ triptolide for H3K36me2 were 13.9\%, 25.2\%, and $35.8 \%$, respectively (Figure 7B). In addition, H3K36 trimethylation was also found to be reduced by triptolide in U266 cells in a dose-dependent manner ${ }^{[17]}$.

\section{Triptolide altered the expression of the histone demethylase} LSD1 in RPMI8226 cells

LSD1 is a flavin-dependent monoamine oxidase that demethylates both di- and mono-methylated $\mathrm{H} 3 \mathrm{~K} 4$ and $\mathrm{H} 3 \mathrm{~K}$, which is a post-translational modification that is associated with gene activation $^{[20-22]}$. To investigate the potential mechanisms by which triptolide downregulates dimethylated H3K4 and dimethylated H3K9, RPMI8226 cells were treated with triptolide $(50,100$, or $150 \mathrm{nmol} / \mathrm{L})$, and LSD1 protein levels were analyzed using an antibody against human LSD1. As shown in Figure 7A, triptolide-treated cells showed significantly higher levels of LSD1 compared with the control $(P<0.05$ vs untreated control), which could be responsible for the decrease in dimethylated H3K4 and dimethylated H3K9. Consistent with the Western-blot results, immunofluorescence analysis showed that there was a significant increase in LSD1 in cells exposed to triptolide (shown in Figure 8).

We extracted total RNA from triptolide-treated RPMI8226 cells and analyzed LSD1 mRNA by real-time PCR to investigate the effects of triptolide on the transcriptional expression of LSD1. As shown in Figure 9A, the levels of LSD1 mRNA in RPMI8226 cells were increased slightly after exposure to triptolide for $48 \mathrm{~h}$ compared with the control, but this change was not statistically significant. Therefore, triptolide could not regulate the activity of LSD1 at the transcriptional level $(P>0.05)$.

\section{Triptolide decreased the expression of the histone demethylase} JMJD2B in RPMI8226 cells

Unlike LSD1, JMJD2B actively mediates the removal of chromosomal tri- and dimethylated H3K36 and H3K9 well before the replication of chromatin ${ }^{[23]}$. We examined whether JMJD2B played a role in the triptolide-mediated induction of H3K36 and H3K9 dimethylation. RPMI8226 cells were treated with triptolide $(50,100$, or $150 \mathrm{nmol} / \mathrm{L})$, and JMJD2B protein levels were analyzed using an antibody against human JMJD2B. As shown in Figure 7A, JMJD2B levels declined as the concentration of triptolide increased $(P<0.05$ vs untreated control). The rates of inhibition by 50,100, and $150 \mathrm{nmol} / \mathrm{L}$ triptolide at $48 \mathrm{~h}$ were $5.5 \%, 16.8 \%$, and $66.5 \%$, respectively, compared with the control ( $P<0.05$ vs untreated control) (Figure $7 \mathrm{~B})$.

To determine whether triptolide affected the transcriptional expression of the JMJD2B gene, we extracted total RNA from triptolide-treated RPMI8226 cells and amplified JMJD2B by semiquantitative real-time PCR. As shown in Figure 9B, triptolide inhibited the mRNA expression of JMJD2B in a dosedependent manner $(P<0.05)$. A low concentration of triptolide

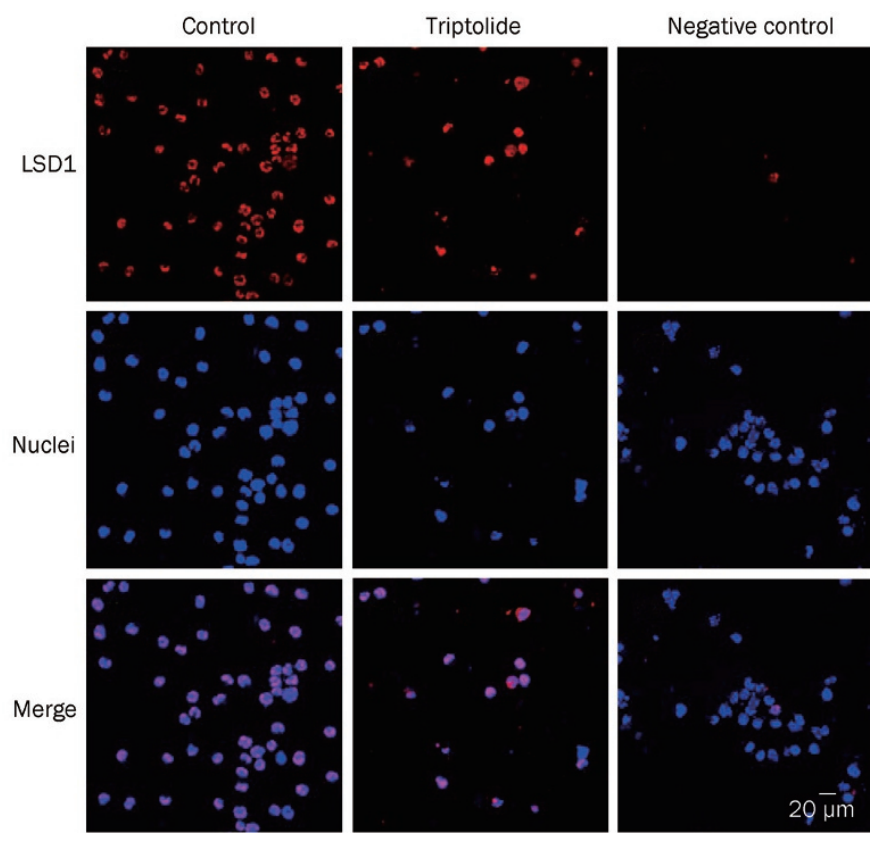

Figure 8. Effect of triptolide on the subcellular localization of LSD1 in RPMI8226 cells. Cells were treated with triptolide $150 \mathrm{nmol} / \mathrm{L}$ for $48 \mathrm{~h}$, and Hoechst 33258 was used to visualize the DNA (which appeared as blue). The expression and subcellular location of LSD1 in control and triptolide-treated groups were visualized via confocal microscope (which appeared red) $(\times 1000)$. LSD1 was distributed in nucleus completely in control group. While in triptolide-treated group a little part of LSD1 was redistributed to the cytoplasm, and distributed in nucleus principally.

\section{A}

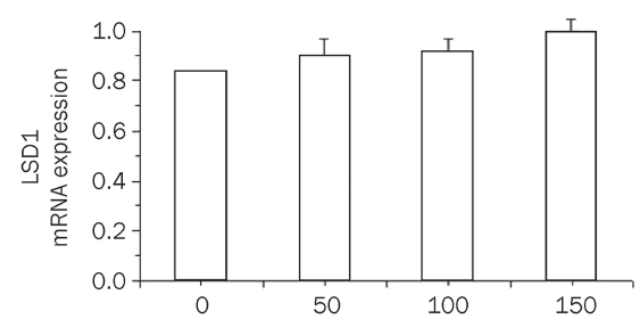

B

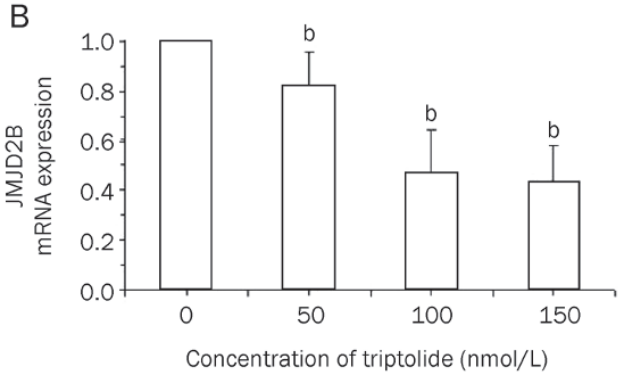

Figure 9. Histone demethylases LSD1 and JMJD2B expression were regulated by triptolide on mRNA level. RPMI8226 cells were treated for $48 \mathrm{~h}$ with increasing triptolide $(50,100,150 \mathrm{nmol} / \mathrm{L})$. Expression of mRNA was then measured by real-time PCR. (A) LSD1 gene expression profile. (B) JMJD2B gene expression profile. Mean $\pm S D$ of at least three independent experiments $\left({ }^{\mathrm{b}} \mathrm{P}<0.05\right)$. 
(50 nmol/L) inhibited the expression of JMJD2B mRNA by $18 \%$. However, the difference in inhibition rates between the 100 and $150 \mathrm{nmol} / \mathrm{L}$ triptolide treatments, which were $53 \%$ and $56 \%$, respectively, was not significant $(P>0.05)$. This result indicates that triptolide regulates JMJD2B activity at the transcriptional level.

\section{Discussion}

MM is a plasma cell neoplasm characterized by the accumulation of terminally differentiated monoclonal plasma cells in the bone marrow and, usually, the presence of monoclonal immunoglobulin in the blood and/or urine ${ }^{[24]}$. MM accounts for approximately $1 \%$ of malignant diseases and is the second most commonly diagnosed hematological malignancy ${ }^{[25]}$. The outcome for patients with MM is highly variable. The median overall survival time is 3-4 years ${ }^{[25]}$. Despite major improvements in treatments including high dose chemotherapy and autologous bone marrow transplantation, the disease remains incurable. Myelomas with no response to initial chemotherapy, incomplete response rates and the eventual emergence of drug resistance remain major obstacles, indicating an urgent need for novel therapeutic agents.

Cancer has traditionally been viewed as primarily a genetic disorder. However, it has become apparent that, in addition to genetic mutations, epigenetic abnormalities also play important roles in the pathogenesis of tumors ${ }^{[26]}$. Epigenetic control mechanisms involve changes in gene expression patterns, due to the modification of DNA and/or histones ${ }^{[15]}$. Modifications to histone $\mathrm{N}$-terminal tails affect chromatin structure, gene transcription, and DNA replication and repair.

Highly specific histone modifications are enriched in target tumor genes and work together with other components to form a complex that interacts with the target genes to induce or inhibit DNA methylation, thereby causing transcriptional repression or activation ${ }^{[27,28]}$. The $\mathrm{N}$-terminal tails of histones undergo several types of post-translational modifications, including methylation, acetylation, phosphorylation and ubiquitination. Unlike other histone modifications, such as acetylation, phosphorylation and ubiquitination, histone methylation is important because of its highly specific effects on gene regulation $^{[14]}$. These modifications remain stable between methylation and demethylation events, which are dynamically regulated by histone methyltransferases and demethylases. It has been demonstrated that abnormalities affecting histone methylation-modifying enzymes lead to aberrant histone modifications, which may occur at gene promoters and induce the improper expression or repression of individual genes that play important roles in tumorigenesis. Recently, the overexpression, amplification and mutation of several histone demethylases have been linked to cell proliferation, cell apoptosis, gene expression, genome stability, and the genesis of cancer.

Triptolide has multiple pharmacological activities, including anti-inflammatory, immunosuppressive, male anti-fertility and anticancer effects ${ }^{[29]}$. Research into its mechanisms of action has revealed that it potently inhibits monocyte activation, activates caspases and other proapoptotic signaling cas- cades, inhibits angiogenesis and reverses drug resistance ${ }^{[30,31]}$. Triptolide is able to induce cell apoptosis by inhibiting nuclear factor $\mathrm{\kappa B}$ activation through the downregulation of Bcl-2 expression and the inhibition of p53 transcriptional activity in p53-wild type human tumors and by upregulating nuclear factor $\mathrm{\kappa B}$ inhibiting protein (IкBa) and $\mathrm{Bax}{ }^{[32-35]}$. Moreover, triptolide has been shown to downregulate various proteins, including heat shock protein 70, Bcr-Abl, survivin, Mcl-1, Akt, $\mathrm{c}-\mathrm{Myc}$, cyclin A/cdk2, cyclin B/cdc2, cyclin D1, and pRb, which may contribute to its anticancer activities under specific conditions $^{[4,36,37]}$. Recently, research has shown that triptolide enhances PS-341-induced apoptosis via the P13k/Akt/NFkappaB pathways in human MM cells ${ }^{[8]}$. Our previous study also suggested that triptolide inhibits proliferation and cellcycle progression by upregulating p21 $1^{\text {wap1/cip1 }}$ and $\mathrm{p} 27^{\mathrm{kip} 1}$ in RPMI8226 cells ${ }^{[38]}$. Nevertheless, the anticancer mechanisms of triptolide remain unclear.

In this study, we found that triptolide inhibited the proliferation of RPMI8226 cells, and its pharmacological effects on cell growth changes occurred in a dose- and time-dependent manner. Triptolide predominantly arrested RPMI8226 cells at $G_{0} / G_{1}$; however, the proportion of cells in $G_{2}$ phase also slightly increased.

Flow cytometric analysis of apoptosis suggested that the extent of apoptosis induced by triptolide varied in relation to the duration of the exposure. The fraction of apoptotic RPMI8226 cells was significantly upregulated following exposure to 50,100 , or $150 \mathrm{nmol} / \mathrm{L}$ triptolide compared with the control $(P<0.01)$.

However, the experiments showed that triptolide had toxic effects on human PBMCs. After staining with Hoechst 33258, RPMI8226 cells treated with triptolide showed typical morphological features of apoptosis. As the drug dose increased, the number of apoptotic cells increased, as indicated by the presence of fragmented nuclei and apoptotic bodies. Ultrastructural changes associated with apoptosis were also visualized by electron microscopy, which showed spherical protuberances containing fragmented and segregated chromatin clumps.

Translocations involving the Ig heavy chain gene locus have been found in approximately $60 \%$ of MM cases with a hypodiploid karyotype, but no common pattern of genetic aberrations characterizes the disease ${ }^{[39]}$. Highly specific histone modifications and methylation-modifying enzymes work together with other components to form a complex that interacts with tumor target genes and is recognized as having a primary role in the control of gene expression and chromatin structure ${ }^{[40]}$.

LSD1, also known as AOF2 and KDM1, was the first histone lysine demethylase to be discovered and belongs to the flavin adenine dinucleotide-dependent enzyme family ${ }^{[41]}$. LSD1 can interact with nuclear receptors; it specifically demethylates H3K4me2/1 and H3K9me2/1 and functions as a transcriptional co-activator or co-repressor ${ }^{[42,43]}$. Whether LSD1 has a tumor suppressive or tumor promoting effect depends on many factors, including the cellular context ${ }^{[14]}$. Amanda has shown that SPR-5 (a Caenorhabditis elegans orthologue of 
LSD1) could increase p53-dependent germ cell apoptosis and plays a unique role in meiotic DNA double-strand break (DSB) repair $^{[44]}$. In addition, knockdown of LSD1 delays the initial induction of p53 in response to DNA damage, which leads to reduced activation of p21 and MDM2, resulting in a decrease in p53-mediated apoptosis. Likewise, in p53-deficient cells, LSD1 can regulate DNA-damage-induced cell death by promoting E2F1 accumulation during DNA damage and the activation of its proapoptotic target gene p73, a major mediator of p53-independent apoptosis ${ }^{[4]}$. In contrast, Huang et al found that knockdown of LSD1 increases the transcriptional activation of $\mathrm{p} 21$ and MDM2 by p53 ${ }^{[46,47]}$. However, the LSD1 complex has been shown to be required for the repressive activity of an oncogenic I kappa B protein, and a functional link has been established between the E3 ligase TBLR1 and NF-kap$\mathrm{paB}^{[48]}$.

In our study, triptolide promoted the expression of LSD1 at the translational level in a dose-dependent manner. LSD1 could exert its proapoptotic effects by directly demethylating non-histone proteins, such as p53 and E2F1 in multiple myeloma cells. LSD1 can also induce apoptosis through its H3K4 demethylase activity. H3K4me2 is highly enriched at transcriptionally competent or active gene promoters. According to the ENCODE pilot project, GM12878 and K562 show significant enrichment for $\mathrm{H} 3 \mathrm{~K} 4 \mathrm{me}$, including large subsets of pluripotency-related or developmentally regulated gene promoters and enhancers ${ }^{[49]}$. For instance, c-Myc expression is downregulated after the loss of H3K4me2 in the c-Myc promoter ${ }^{[46]}$. We have consistently found high H3K4me2 expression in multiple myeloma cells, and triptolide was observed to downregulate H3K4me2 protein expression in a dose-dependent manner. The reduction in H3K4me2 promoted by LSD1 strongly inhibited the epigenetic control of anti-apoptotic gene transcription in RPMI8226 cells, which is probably one of the most important anti-MM mechanisms of triptolide.

Another family of histone lysine demethylases that are structurally different from LSD1 has been described, all of which share a conserved jumonji $\mathrm{C}(\mathrm{JmjC})$ domain $^{[50]}$. The JMJD2 family of histone demethylases is amplified in human cancers ${ }^{[51]}$. However, little is known about the physiological or tumorigenic roles of these proteins. The depletion of JMJD2 has previously been demonstrated to increase DNA doublestrand breaks in the adult germ line, resulting in ATR/p53dependent apoptosis ${ }^{[51]}$. Hypoxia-inducible factor-1 alpha (HIF-1 alpha) may cooperate with estrogen receptor alpha (ER alpha) to regulate JMJD2B, which drives breast cancer cell proliferation under hypoxic conditions and regulates the expression of cell-cycle genes, such as CCND1, CCNA1, and WEE $1^{[52]}$. Moreover, JMJD2B has been suggested as a potential novel target gene for p53 that can mediate the DNA damage response and may be protective against apoptosis ${ }^{[53]}$. As a member of the JMJD2 family, JMJD2B is capable of reversing the lysine trimethylation of $\mathrm{H} 3 \mathrm{~K} 9 \mathrm{me} 3$ at pericentric heterochromatin in mammalian cells ${ }^{[54]}$. In addition, the removal of $\mathrm{H} 3 \mathrm{~K} 9 \mathrm{me} 3$ marks by JMJD2B may prevent the induction of senescence, which is a specific form of irreversible growth arrest and an important process for the suppression of tumorigenesis $^{[23,55]}$. Therefore, cancer cells that highly express JMJD2B may evade this important tumor suppression mechanism $^{[55]}$.

Our experiments demonstrated that histone H3K9 and H3K36 dimethylation were dose-dependently reduced by triptolide, as were JMJD2B mRNA and protein levels. These results suggest that the downregulation of $\mathrm{H} 3 \mathrm{~K} 9 \mathrm{me} 2$ was partly due to the decrease in JMJD2B in RPMI8226 cells because the levels of $\mathrm{H} 3 \mathrm{~K} 9 \mathrm{me} 2$ formed by the demethylation of H3K9me3 were significantly reduced. Triptolide may exert its proapoptotic effects partly by directly downregulating JMJD2B in multiple myeloma cells.

In addition, JMJD2B could demethylate trimethylated H3K36 to dimethylated H3K36. H3K36me2/me3 are enriched mostly in the transcribed region of active genes and are associated with the later stages of transcription in actively transcribed regions ${ }^{[18]}$. However, a direct association between H3K36me2 and proapoptotic genes has not been proven; further investigation will be required to clarify this relationship. In our study, the downregulation of JMJD2B may be partially responsible for the reduction in $\mathrm{H} 3 \mathrm{~K} 9 \mathrm{me} 2$ and $\mathrm{H} 3 \mathrm{~K} 36 \mathrm{me} 2$ in triptolide-treated cells. LSD1 and JMJD2B are assumed to be two targets for triptolide as an anti-MM drug.

In summary, our experiments showed that triptolide inhibited proliferation and induced apoptosis and $G_{0} / G_{1}$ cell cycle arrest in the MM cell line RPMI8226 in a dose-dependent manner. Moreover, this study provided the first evidence that triptolide could restore epigenetic changes by regulating the histone demethylases LSD1 and JMJD2B, thereby offering a novel view of the anti-MM mechanism of triptolide.

\section{Abbreviations}

$\mathrm{MM}$, multiple myeloma; $\mathrm{BM}$, bone marrow; PI, propidium iodide; DMSO, dimethylsulfoxide; MTT, 3-(4,5-dimethylthiazol-2-yl)-2, 5-diphenyltetrazoliumbromide; PBMC, peripheral blood mononuclear cells; SDS, sodium dodecylsulfate; TBS, Tris-buffered saline; H3K4me2, dimethyl-lysine 4 on histone H3; H3K9me2, dimethyl-lysine 9 on histone H3; H3K36me2, dimethyl-lysine 36 on histone H3; ECL, enhanced chemiluminescence; BSA, bovine serum albumin; LSD1, lysine-specific demethylase 1; JMJD2B, the second member of the Jumonji domain 2 family of proteins. PBS, phosphate-buffered saline.

\section{Acknowledgements}

This work was supported by two grants from the National Natural Sciences Foundation of China (№ 30700882 and № 81070429).

\section{Author contribution}

Yan CHEN, Ling-lan ZENG, and Chun ZHANG designed the research; Lu WEN, Rui LI, Fei ZHAO, and Yuan LIU performed the experiments; Lu WEN analyzed the data and wrote the paper. 


\section{References}

1 Carter BZ, Mak DH, Schober WD, McQueen T, Harris D, Estrov Z, et al. Tliptolide induces caspase-dependent cell death mediated via the mitochondfial pathway in leukemic cells. Blood 2006; 108: 630-7.

2 Kiviharju TM, Lecane PS, Sellers RG, Peehl DM. Antiproliferative and proapoptotic activities of triptolide (PG490), a natural product entering clinical trials, on primary cultures of human prostatic epithelial cells. Clin Cancer Res 2002; 8: 2666-74.

3 Pigneux A, Mahon FX, Uhalde M, Jeanneteau M, Lacombe F, Milpied N, et al. Triptolide cooperates with chemotherapy to induce apoptosis in acute myeloid leukemia cells. Exp Hematol 2008; 36: 1648-59.

4 Yang SM, Chen JG, Guo Z, Xu XM, Wang LP, Pei XF, et al. Triptolide inhibits the growth and metastasis of solid tumors. Mol Cancer Ther 2003; 2 : 65-72.

5 Zhang C, Cui GH, Liu F, Wu QL, Chen Y. Inhibitory effect of triptolide on lymph node metastasis in patients with non-Hodgkin lymphoma by regulating SDF-1/CXCR4 axis in vitro. Acta Pharmacol Sin 2006; 27 : 1438-46.

6 Zhang C, Cui GH, Liu F, Wu QL, Chen Y. Effects of triptolide on cell proliferation and CXCR4 expression in Burkitt's lymphoma Raji cells in vitro. Chin J Cancer Res 2007; 19: 27-31.

7 Carter BZ, Mak DH, Schober WD, Dietrich MF, Pinilla C, VassileV LT, et al. Triptolide sensitizes AML cells to TRAlL-induced apoptosis via decrease of XIAP and p53-mediated increase of DR5. Blood 2008; 111: 3742-50.

8 Yang M, Huang J, Pan HZ, Jin J. Triptolide overcomes dexamethasone resistance and enhanced PS-341-induced apoptosis via PI3k/Akt/NFkappa B pathways in human multiple myeloma cells. Int J Mol Med 2008; 22: 489-96.

$9 \mathrm{Ng}$ MHL, To KW, Lo KW, Chan S, Tsang KS, Cheng SH, et al. Frequent death-associated protein kinase promoter hypermethylation in multiple myeloma. Clin Cancer Res 2001; 7: 1724-9.

10 Galm O, Wilop S, Reichelt J, Jost E, Gehbauer G, Herman JG, et al. DNA methylation changes in multiple myeloma. Leukemia 2004; 18 : 1687-92.

11 Chim CS, Pang R, Fung TK, Choi CL, Liang R. Epigenetic dysregulation of Wnt signaling pathway in multiple myeloma. Leukemia 2007; 21 : 2527-36.

12 Lohrum M, Stunnenberg HG, Logie C. The new frontier in cancer research: Deciphering cancer epigenetics. Int J Biochem Cell Biol 2007; 39: 1450-61.

13 Vakoc CR, Mandat SA, Olenschock BA, Blobel GA. Histone H3 lysine 9 methylation and HP1 gamma are associated with transcription elongation through mammalian chromatin. Blood 2005; 106: 1734.

14 Lim S, Metzger E, Schule R, Kirfel J, Buettner R. Epigenetic regulation of cancer growth by histone demethylases. Int J Cancer 2010; 127 : 1991-8.

15 Zhao F, Chen Y, Li R, Liu Y, Wen L, Zhang C. Triptolide alters histone $\mathrm{H} 3 \mathrm{~K} 9$ and $\mathrm{H} 3 \mathrm{~K} 27$ methylation state and induces $\mathrm{G}_{0} / \mathrm{G}_{1}$ arrest and caspase-dependent apoptosis in multiple myeloma in vitro. Toxicology 2010; 267: 70-9.

16 Eissenberg JC, Shilatifard A. Histone H3 lysine 4 (H3K4) methylation in development and differentiation. Dev Biol 2010; 339: 240-49.

17 Zhao F, Chen Y, Zeng LL, Li R, Zeng R, Wen L, et al. Role of triptolide in cell proliferation, cell cycle arrest, apoptosis and histone methylation in multiple myeloma U266 cells. Eur J Pharmacology 2010; 646: 1-11.

18 Zhao F, Chen Y, Zeng LL, Li R, Zeng R, Wen L, et al. Effects of triptolide on RIZ1 expression, proliferation, and apoptosis in multiple myeloma U266 cells. Acta Pharmacol Sin 2010; 31: 733-40.

19 Strahl BD, Grant PA, Briggs SD, Sun ZW, Bone JR, Caldwell JA, et al.
Set2 is a nucleosomal histone H3-selective methyltransferase that mediates transcriptional repression. Mol Cell Biol 2002; 22: 1298306.

20 Forneris F, Battaglioli E, Mattevi A, Binda C. New roles of flavoproteins in molecular cell biology: Histone demethylase LSD1 and chromatin. FEBS J 2009; 276: 4304-12.

21 Sharma A, Heuck CJ, Fazzari MJ, Mehta J, Singhal S, Greally JM, et al. DNA methylation alterations in multiple myeloma as a model for epigenetic changes in cancer. Wiley Interdiscip Rev Syst Biol Med 2010; 2: 654-69.

22 Wang GG, Allis CD, Chi P. Chromatin remodeling and cancer, part I: covalent histone modifications. Trends Mol Med 2007; 13: 363-72.

23 Fodor BD, Kubicek S, Yonezawa M, O'Sullivan RJ, Sengupta R, PerezBurgos L, et al. Jmjd2b antagonizes H3K9 trimethylation at pericentric heterochromatin in mammalian cells. Genes \& Development 2006; 20: 1557-62.

24 Moreaux J, Hose D, Bonnefond A, Reme T, Robert N, Goldschmidt $\mathrm{H}$, et al. MYEOV is a prognostic factor in multiple myeloma. Exp Hematology 2010; 38: 1189-98.

25 Lopez-Otero A, Ruiz-Delgado GJ, Hernandez-Arizpe A, Ruiz-Arguelles A, Ruiz-Arguelles GJ. The flow-cytometric DNA content of the plasma cells of patients with multiple myeloma is a prognostic factor: a single institution experience. Hematology 2010; 15: 378-81.

26 Feinberg AP, Ohlsson R, Henikoff $S$. The epigenetic progenitor origin of human cancer. Nat Rev Genet 2006; 7: 21-33.

27 Ballestar E, Wolffe AP. Methyl-CpG-binding proteins - Targeting specific gene repression. Eur J Biochem 2001; 268: 1-6.

28 Schlesinger Y, Straussman R, Keshet I, Farkash S, Hecht M, Zimmerman J, et al. Polycomb-mediated methylation on Lys27 of histone $\mathrm{H} 3$ pre-marks genes for de novo methylation in cancer. Nat Genet 2007; 39: 232-6.

29 Shen JA, $\mathrm{He} \mathrm{CH}$. Isolation and purification of triptolide from the leaves of tripterygium wilfordii Hook F. Chin J Chem Engineering 2010; 18 : 750-4.

30 Liu QY, Chen TY, Chen GY, Shu XL, Sun A, Ma PC, et al. Triptolide impairs dendritic cell migration by inhibiting CCR7 and COX-2 expression through PI3-K/Akt and NF-kappa B pathways. Mol Immunol 2007; 4: 2686-96.

31 Zhou B, Miao Z, Deng G, Ding J, Yang Y, Feng H, et al. Synthesis and biological evaluation of novel triptolide analogues for anticancer activity. Bioorg Med Chem Lett 2010; 20: 6217-21.

32 Jiang $\mathrm{XH}$, Wong BCY, Lin MCM, Zhu GH, Kung HF, Jiang SH, et al. Functional p53 is required for triptolide-induced apoptosis and AP-1 and nuclear factor-kappa B activation in gastric cancer cells. Oncogene 2001; 20: 8009-18.

33 Lin J, Chen LY, Lin ZX, Zhao ML. The effect of triptolide on apoptosis of glioblastoma multiforme (GBM) cells. J Int Med Res 2007; 35 : 637-43.

34 Lou YJ, Jie J, Wang YG. Triptolide inhibits transcription factor NFkappaB and induces apoptosis of multiple myeloma cells. Leukemia Res 2005; 29: 99-105.

35 Zhou GX, Ding XL, Huang LF, Zhang H, Wu SB, Cheng JP, et al. Apoptosis of human pancreatic cancer cells induced by Triptolide. World J Gastroenterol 2008; 14: 1504-9.

36 Lou YJ, Jin J. Triptolide down-regulates bcr-abl expression and induces apoptosis in chronic myelogenous leukemia cells. Leukemia \& Lymphoma 2004; 45: 373-6.

37 Phillips PA, Dudeja V, McCarroll JA, Borja-Cacho D, Dawra RK, Grizzle WE, et al. Triptolide induces pancreatic cancer cell death via inhibition of heat shock protein 70. Cancer Res 2007; 67: 9407-16.

38 Liu YA, Zeng LL, Chen Y, Zhao F, Li R, Zhang C, et al. Triptolide inhibits 
cell growth and induces $G_{0}-G_{1}$ arrest by regulating $P 21^{\text {wap } 1 / \text { cip } 1}$ and P27 ${ }^{\text {kip1 }}$ in human multiple myeloma RPMI-8226 cells. Chin J Cancer Res 2010; 22: 141-7.

39 Tshuikina M, Jernberg-Wiklund H, Nilsson K, Oberg F. Epigenetic silencing of the interferon regulatory factor ICSBP/IRF8 in human multiple myeloma. Exp Hematol2008; 36: 1673-81.

40 Yadav S, Singhal J, Singhal SS, Awasthi S. hSET1: A novel approach for colon cancer therapy. Biochem Pharmacol 2009; 77: 1635-41.

41 Shi YJ, Lan F, Matson C, Mulligan P, Whetstine JR, Cole PA, et al. Histone demethylation mediated by the nuclear arnine oxidase homolog LSD1. Cell 2004; 119: 941-53.

42 Garcia-Bassets I, Kwon YS, Telese F, Prefontaine GG, Hutt KR, Cheng $\mathrm{CS}$, et al. Histone methylation-dependent mechanisms impose ligand dependency for gene activation by nuclear receptors. Cell 2007; 128 : 505-18.

43 Metzger E, Wissmann M, Yin N, Muller JM, Schneider R, Peters A, et al. LSD1 demethylates repressive histone marks to promote androgenreceptor-dependent transcription. Nature 2005; 437: 436-9.

44 Nottke AC, Beese-Sims SE, Pantalena LF, Reinke V, Shi Y, Colaiacovo MP. SPR-5 is a histone H3K4 demethylase with a role in meiotic double-strand break repair. Proc Natl Acad Sci U S A 2011; 108 : 12805-10.

45 Kontaki H, Talianidis I. Lysine methylation regulates E2F1-induced cell death. Mol Cell 2010; 39: 152-60.

46 Koche RP, Smith ZD, Adli M, Gu H, Ku M, Gnirke A, et al. Reprogramming factor expression initiates widespread targeted chromatin remodeling. Cell Stem Cell 2011; 8: 96-105.

47 Huang J, Sengupta R, Espejo AB, Lee MG, Dorsey JA, Richter M, et al. p53 is regulated by the lysine demethylase LSD1. Nature 2007; 449:
105-8.

48 Keutgens A, Shostak K, Close P, Zhang X, Hennuy B, Aussems M, et al. The repressing function of the oncoprotein $B C L-3$ requires $C t B P$, while its polyubiquitination and degradation involve the E3 ligase TBLR1. Mol Cell Biol 2010; 30: 4006-21.

49 Huda A, Bowen NJ, Conley AB, Jordan IK. Epigenetic regulation of transposable element derived human gene promoters. Gene 2011; 475: 39-48.

50 Lim S, Janzer A, Becker A, Zimmer A, Schule R, Buettner R, et al. Lysine-specific demethylase 1 (LSD1) is highly expressed in ER-negative breast cancers and a biomarker predicting aggressive biology. Carcinogenesis 2010; 31: 512-20.

51 Black JC, Allen A, Van Rechem C, Forbes E, Longworth M, Tschöp K, et al. Conserved antagonism between JMJD2A/KDM4A and HP1Y during cell cycle progression. Mol Cell 2010; 40: 736-48.

52 Yang J, Jubb AM, Pike L, Buffa FM, Turley H, Baban D, et al. The Histone Demethylase JMJD2B Is Regulated by Estrogen Receptor alpha and Hypoxia, and Is a Key Mediator of Estrogen Induced Growth . Cancer Res 2010; 70: 6456-66.

53 Adamsen BL, Kravik KL, Clausen OPF, De Angelis PM. Apoptosis, cell cycle progression and gene expression in TP53-depleted HCT116 colon cancer cells in response to short-term 5-fluorouracil treatment. Int J Oncol 2007; 31: 1491-500.

54 Palomera-Sanchez Z, Zurita M. Open, repair and close again: chromatin dynamics and the response to UV-induced DNA damage. DNA Repair (Amst) 2011; 10: 119-25.

55 Cloos PAC, Christensen J, Agger K, Maiolica A, Rappsilber J, Antal T, et al. The putative oncogene GASC1 demethylates tri- and dimethylated lysine 9 on histone H3. Nature 2006; 442: 307-11. 